\title{
El debate público envenenado y los límites de la regulación estatal: por una alfabetización digital ante el problema de las fake news
}

\section{The poisoned public debate and the limits of state regulation: for a digital literacy against the fake news}

Lucas Vianna

Universidade Regional do Noroeste do Estado do Rio Grande do Sul, Brasil lucasoliveiravianna@gmail.com https://orcid.org/0000-0002-3975-7188

\author{
Matheus T. Carvalho-Mendonça \\ Universidad Nacional de La Plata, Argentina \\ tcarvalho@dr.com \\ https://orcid.org/0000-0002-1094-1213
}

\begin{abstract}
Resumen
Además de los esfuerzos deliberados por distorsionar o desinformar, los errores involuntarios detectados por el público $-\mathrm{y}$ la sospecha de que pueda haber otros no identificados - han reforzado una postura escéptica entre el público sobre la supuesta veracidad de la noticia. En la era de la llamada posverdad, no es exagerado decir que la principal preocupación de las ciencias sociales tras el debate público se ve totalmente obstaculizada por la difusión de noticias falsas y el supuesto inicio del colapso de las democracias liberales, ha sido una sensación colectiva de conmoción, indignación. y desesperación ante la creciente prevalencia de noticias falsas. Este artículo se centra en el fenómeno de las fake news, sus efectos en el contexto de las disputas políticas y los marcos regulatorios como supuesta solución. Se pretende demostrar que la alfabetización digital aparece como la solución más adecuada para mitigar este problema, sin afectar la libertad de expresión en el ámbito discursivo público.
\end{abstract}

\section{Palabras clave}

Fake news, posverdad, alfabetización digital, democracia liberal, regulación estatal, libertad de expresión.

Forma sugerida de citar: Vianna, L., \& Carvalho-Mendonça, M.T. (2021). El debate público envenenado y los límites de la regulación estatal: Por una alfabetización digital ante el problema de las fake news. Univeristas, 34, pp. 19-40. 


\begin{abstract}
In addition to the deliberate efforts to distort or misinform, the unintentional errors detected by the public - and the suspicion that there may be others not identified - have reinforced a skeptical stance among the public about the alleged veracity of the news. In the era of the so-called post-truth, it is no exaggeration to say that the main concern of the social sciences after the public debate has been completely hampered by the spread of false news and the supposed beginning of the collapse of liberal democracies, has been a collective sensation of shock, indignation. and despair at the increased prevalence of false news. This paper focuses on the phenomenon of fake news, its effects in the context of political disputes and regulatory frameworks as an alleged solution. It is intended to demonstrate that digital literacy appears as the most adequate solution to mitigate this problem, without affecting freedom of expression in the public discursive sphere.
\end{abstract}

Keywords

Fake news, post-truth, digital literacy, liberal democracy, state regulation, freedom of speech.

\title{
Introducción y estado de la cuestión
}

"Cada audiencia tiene su propio universo de discurso y [...] humanamente hablando, un hecho es solo un hecho en algún universo de discurso" (Park, 1940, p. 649). La difusión de noticias falsas, especialmente en política, no es nada nuevo, pero Internet ha popularizado el uso del fenómeno llamado fake news. Incluso el Papa Francisco, ícono de la religión cristiana, se vio afectado por este fenómeno. El religioso afirmó: "la desinformación es probablemente el mayor pecado que puede cometer un medio de comunicación, porque dirige a la opinión pública en una sola dirección y omite parte de la verdad" (El País, 2016). Se cree que las fake news surgen de información real, pero que se malinterpreta, es decir, se distorsiona y se difunde como verdad, hasta que influye en el público al que se llega. En resumen:

El juego es tan antiguo como la humanidad. Es una cuestión de engaños y mentiras. La novedad está, como en todo lo demás estos días, en lo que los ordenadores y la red mundial permiten hacer con él. (Mesquita, 2018, p. 33) 
Por increíble que parezca, Macedonia es considerada el centro de la industria de las noticias falsas en el mundo. Esto se debe a la mano de obra barata y al alto desempleo. Periodistas que realizaron una investigación a través de empresas de verificación de datos y expertos incluso entrevistaron a uno de los llamados Vele's Boys, un grupo de la ciudad de Veles, en el interior de Macedonia, que crea y difunde noticias falsas, y concluye que la motivación está dada. sin ideología ni preocupación alguna por la veracidad de los hechos, de manera totalmente económica, llegando a generar 20000 dólares semanales.

La mayoría de las incursiones científicas con respecto a las fake news se han centrado en cuestiones de producción, como la ubicación y las posibles motivaciones de varios proveedores de desinformación, el cambiante panorama geopolítico de la guerra de la información, los beneficios económicos para los medios. mecanismos de comunicación y búsqueda y la necesidad y conveniencia de implementar restricciones técnicas y/o financieras que minimicen la difusión de noticias falsas, entre otras. El enfoque en temas de producción es importante y todos estos son casos válidos cuya discusión es pertinente. Sin embargo, este artículo, aunque tiene en cuenta a algunos de los puntos anteriores, pretende abordar algunas dinámicas de recepción crítica que podrían estar subyacentes a la mayor presencia de noticias falsas en el entorno contemporáneo que en el pasado.

Para ello, se destaca como de especial relevancia un enfoque interseccional entre la Sociología y el Derecho, para entender no solo cómo abordar el problema a través de una herramienta legislativa, sino también cómo interpretar su advenimiento desde los contextos histórico, sociológico y cultural que sirvieron como lugar de nacimiento, es decir, la posmodernidad y la posverdad, eligiendo estos como un panorama teórico.

Finalmente, se procede a un breve análisis de las medidas que se han utilizado en todo el mundo para afrontar el problema, con una breve reflexión crítica sobre su efectividad relativa, tanto a partir de las estructuras teóricas previamente establecidas como de los datos empíricos. que han sido planteados por las Humanidades y las Ciencias Sociales.

\section{Noticias falsas como semilla y fruto de la posverdad}

Para una adecuada comprensión del problema de las fake news, es fundamental que el fenómeno sea contextualizado en el panorama sociocultural 
en el que se inserta, para lo cual se muestran categorías sociológicas útiles como la posmodernidad y la posverdad.

La Universidad de Oxford, al elegir, en 2016, el término "posverdad" como la palabra del año, definió la expresión como "un sustantivo que se relaciona o denota circunstancias en las que los hechos objetivos tienen menos influencia en la formación de la opinión pública que que apela a la emoción y las creencias personales" (Oxford, 2016). Es necesario aclarar - como lo hace McIntyre (2018) - que el prefijo "post" del neologismo en cuestión no se refiere a la idea de "después" de la verdad, en un sentido temporal como en "posguerra", por ejemplo - , sino en el sentido de que la verdad ha sido superada, que es irrelevante. Se trata, en realidad, de una situación cultural caracterizada por una opinión pública afectada por el pathos público, en la que "importa menos el reclamo de validez que la expectativa de que la expectativa del deseo de que la información se cumpla" (Giacoia Junior, 2017), posibilitando el surgimiento de un espacio público "donde la tendencia es practicar y difundir el uso de argumentos [...] más ligados a la dimensión emocional que a la dimensión racional y fundamentada", por lo que "las pruebas de refutación generalmente son ignoradas o devaluadas" (Cardoso et al., 2012, p. 15).

Ahora bien, comprender con precisión el concepto de posverdad es un dilema casi insoluble, "si consideramos todas las peculiaridades que implican la constitución del discurso, o si tenemos en cuenta la propia complejidad del concepto de verdad" (Borges Júnior, 2019, p. 527), que sería incluso uno de los temas más fundamentales sobre los que la filosofía occidental emprendería largas reflexiones. Quizás la discusión entre Sócrates y los sofistas y la crítica del primero sobre la concepción de la verdad del segundo sea un punto importante como ejemplo de esto (Reale \& Antiseri, 2014). Con respecto a la posibilidad de versiones rivales o perspectivas de la verdad ya en la cultura clásica, Borges Júnior explica que:

Mientras que la filosofía de Sócrates se basa en una concepción única, inmutable y absoluta de la verdad, la filosofía sofista defenderá la relatividad de la verdad, su posibilidad de transformación según la operación de $\lambda o ́ \gamma o \varsigma$ (logos). Según Protágoras, algo puede así anunciarse como verdad o como mentira, como a favor o en contra de un determinado argumento, y será esta flexibilidad del concepto de verdad y la posibilidad de manipularlo para A o para B, para sí o no, en el que se construirán los ejercicios de persuasión y las clases de retórica [...]. Ahora mismo, nos enfrentamos a pensar en la ver- 
dad como absoluta o relativa, poniendo así en cuestión cualquier noción de objetividad o un retrato fiel de las cosas o del mundo. Esta disputa insoluble contribuiría, en gran medida, al nacimiento de lo que hoy llamaríamos política. (Borges Júnior, 2019, p. 527)

En esta dinámica narrativa política, Arendt, a su vez, es consciente de un grave riesgo: la posibilidad, por parte de la propia política, de alterar la factualidad de las cosas a partir de la "fabricación" de realidades paralelas, realidades que buscan legitimar ciertos discursos. La autora reflexiona:

[...] si las mentiras políticas modernas son tan grandes que requieren una reordenación completa de toda la trama fáctica, la creación de otra realidad, por así decirlo, en la que encajen sin parches, fallas o grietas, al igual que los hechos encajan en su propio contexto original, ¿qué impide que estas nuevas historias, imágenes y pseudo-hechos se conviertan en un sustituto adecuado de la realidad y la factualidad? (Arendt, 2014, p. 313)

Tales discursos terminan reordenando su propia facticidad y se construyen con el propósito de ceñirse a ella sin ningún indicio capaz de denunciar su falsedad. Esta adhesión se opera a través de una forma muy bien organizada, llamada por Arendt (2014) "mentira política moderna", muy diferente a las formas utilizadas por la "mentira política tradicional". Siguiendo la observación de la autora, la mentira política moderna - en la que se basarían principalmente las estructuras de los regímenes totalitarios - parece trasladar a un contexto doméstico el refuerzo de ciertas versiones de la realidad, historias ilusorias a menudo creadas en el sentido de brindar nuevas descripciones, también bajo sesgos delimitados, ciertos eventos que tienen lugar en estas sociedades. Como ejemplo, Arendt (2014) comenta los esfuerzos del general Charles De Gaulle por volver a contar la historia de Francia en la Segunda Guerra Mundial, presentándola como altiva y poderosa, indiferente a los años en que fue pisoteada por los alemanes; o incluso el régimen de Josef Stalin, responsable de borrar el nombre de Trotsky de la historia de la Revolución Rusa.

Sin embargo, las mentiras políticas modernas, al crear ciertas imágenes que refuerzan lo que quieren contar, producen paradójicamente una especie de autoengaño, del que se vuelve extremadamente difícil y complejo distinguir entre verdad y mentira. Esto solo es posible gracias a la creación 
de un sofisticado aparato de "manipulación masiva de hechos y opiniones" (Arendt, 2014, p. 311), en el que la publicidad ocupa un lugar central.

En definitiva, la posverdad es la noción de que las creencias o impresiones son constitutivas de la realidad (Cunha Filho, 2019), animando a los individuos a distorsionar los hechos para moldearlos de acuerdo con sus opiniones, y no al revés (McIntyre, 2019). No es de extrañar, por tanto, que su estallido se produzca en el contexto sociocultural de la posmodernidad.

La posmodernidad ofrece un apoyo filosófico a la posverdad a la medida en que proclama que todos los hechos sociales se construyen socialmente y que los argumentos sobre un determinado hecho político o social se asocian invariablemente a una narrativa específica (Cunha Filho, 2019). El énfasis emotivista e identitario del pensamiento posmoderno también demuestra fertilidad para el surgimiento de noticias falsas, ya que, en este entorno sociocultural, "las elecciones [...] se basan mucho más en razones sensibles y emocionales que en el razonamiento lógico y en la información precisa" (Genesini, 2018, p. 48).

Además, la elección del blanco - muy precisa en esa definición - apunta a una "anti-verdad", fundamental para entender el "post". Lara Mesquita (2018, p. 33) afirma objetivamente: "esto es mentira, pero su uso con el objetivo específico de subvertir o socavar la democracia, único sistema de constitución del poder del Estado en el que la 'opinión pública' es el factor determinante".

El caso es que el fenómeno de la posverdad -y la difusión de noticias falsas como mecanismo para la construcción de una narrativa de eso- distorsiona y daña directamente la calidad de las democracias liberales, como explica el autor:

Armar de la mano de la "opinión pública" la revocatoria, el referéndum y la iniciativa para hacer prevalecer efectivamente su voluntad sobre la de sus representantes electos, es todavía un privilegio de muy pocos. Sin embargo, el concepto general fue adoptado universalmente como un sueño. Nadie puede enfrentarlo impunemente. Incluso las dictaduras necesitan venderse a sí mismas como "exceso de democracia" e incluir en sus disfraces institucionales elementos que al menos se asemejen a las instituciones democráticas. La conversión paulatina de la lucha contra la democracia "burguesa", de una disputa entre verdades enfrentadas a la destrucción del concepto mismo de verdad, incluye el reconocimiento de la relación indisoluble entre democracia y verdad. Admitiendo que donde está bien plantada, la democracia solo puede destruirse desde adentro, a partir de la deliberación de la mayoría con- 
tra sí misma, y que solo el engaño puede producir este efecto, rinde homenaje a la superioridad moral que sus enemigos siempre le han negado a lo largo de la historia del siglo XX. (Mesquita, 2018, pp. 34-35)

Frente a este alboroto, algunos autores han entendido la quiebra del paradigma de la democracia liberal, que presentaría una visión formalista de la soberanía popular, ejercida únicamente a través del voto, pero sin participación efectiva en las políticas públicas, así como amputada de la noción social de ética en comunidad.

En esta dirección, Manuel Castells (2018) entiende que la crisis de este modelo está "adoptando múltiples formas", entre ellas, "la subversión de las instituciones democráticas por parte de caudillos narcisistas que se apoderan de los manantiales del poder del disgusto de las personas con podredumbre institucional". "El puro y simple retorno a la brutalidad irrestricta del Estado en buena parte del mundo, desde Rusia a China, desde el África neocolonial a los neofascismos en Europa del Este y a las mareas dictatoriales en América Latina" y, en lo que a este artículo se refiere, "la manipulación mediática de las esperanzas frustradas por los encantadores de serpientes [...]". En otro trabajo, denominado "Sociedade em Rede", el autor sostiene que el fenómeno de las fake news es especialmente demostrativo del colapso del sistema político liberal (Castells, 1999). Con respecto a eso, Mesquita escribe:

En la etapa pre-tecnológica, casi artesanal, lo que se convertiría en "posverdad" evolucionó del "patrullaje ideológico" ante el poder a la represión y la agresión armada de la disputa por la hegemonía geoestratégica, hasta que fluyó, después de detenida en su avance militar, en un intento de imponer una "hegemonía cultural" en busca del "consentimiento social" de un conjunto de convicciones, normas morales y reglas de conducta sembradas de un minucioso trabajo de "superación" inducido por creencias y sentimientos establecidos, en dirección a la autoinmolación de las democracias, que se obtendrá mediante el "control de los medios de difusión cultural de la burguesía", y la "cooptación de artistas, profesores e intelectuales orgánicos" al servicio de la conquista del poder político. (Mesquita, 2018, pp. 35-36)

En este sentido, las noticias falsas se nutren de la posverdad, al mismo tiempo que constituyen una herramienta para su construcción, constituyendo así un verdadero círculo vicioso. La interrelación entre la aparición de las fake news y el advenimiento del propio entorno digital, que por diferentes cuestiones - algunas relacionadas con la propia naturaleza del medio- no 
puede pasarse por alto, tiene diferentes criterios de validación en relación con los medios periodísticos clásicos (McDougall et al., 2018). Mientras que en los medios físicos tradicionales el beneficio provenía de las suscripciones de los lectores, las plataformas de noticias en el medio digital, al ser gratuitas, obtienen sus ingresos de los anuncios que se muestran en sus respectivas páginas, lo que:

Introduce un factor en la emisión de fake news motivacional que contribuye a su existencia: la dimensión económica de las instituciones periodísticas o de otro tipo, es decir, característica en un modelo comercializable en Internet basado en anuncios. (Cardoso et al., 2018, p. 19)

De esta manera, los portales de medios con un historial de confiabilidad y ética periodística están de a poco siendo reemplazados por alternativas digitales que compiten ávidamente entre sí por los usuarios (McDougall et al., 2018). Este mecanismo permite a las empresas utilizar el llamado "clickbait", un artificio según el cual los portales, "utilizando una relación directa entre el número de visualizaciones y se producen recetas, títulos y/o contenidos que, de forma deliberada, sirven para que los usuarios hagan clic", reforzando la estrecha correlación" entre las fake news y el aspecto emocional cuestionado por la noción de posverdad", ya que "los estudios confirman la tendencia de los usuarios a compartir mucho más las noticias caracterizadas por una lenguaje y contenido sensacional y emocionante" (Cardoso et al., 2018, p. 19).

En este nuevo entorno, el éxito de un portal depende no tanto de la confiabilidad histórica de su contenido o de la ética periodística, sino de su facilidad de ubicación en los medios y del uso de mensajes personalizados para captar la atención del público deseado (Hobbs, 2017). Este sistema contribuye a la difusión de noticias falsas, ya que es más probable que se compartan a través de los medios y viajan más rápido que el contenido real (Vosoughi et al., 2018). Esto se debe en gran parte a la capacidad de las fake news para dialogar con el patetismo del lector - para instrumentalizar una palabra aristotélica - y en ello evocar una profunda simpatía y emociones intensas, como la ansiedad o la ira, que dan lugar a más compartir que contenido neutro (McDougall et al., 2018).

De hecho, las fake news, en su sentido más amplio, pueden existir "teóricamente desde el primer proceso político de la humanidad", pero es "con el surgimiento de los medios de comunicación que se crearon las condiciones para que este fenómeno se convierta en una dimensión fundamental de 
la vida social y política" (Cardoso et al., 2018, p. 19). Por tanto, "la novedad no está en las fake news en sí, sino en la aparición de un instrumento capaz de reproducirlas y difundirlas con una amplitud y rapidez sin precedentes" (Frias-Filho, 2018). Por tanto, aunque el fenómeno no es inusual, es la dimensión actual que asume la que exige nuevos enfoques.

Aunque para algunas personas las noticias falsas pueden parecer inofensivas, varios estudios han demostrado lo contrario (Balem, 2017). Además de los efectos obvios del engaño en la toma de decisiones, la exposición continua a información errónea puede llevar a las personas a dejar de creer en los hechos por completo y a dudar del valor mismo de la ciencia y la evidencia científica (Van der Linden et al., 2017), como se observó claramente en la negación generalizada de los brasileños con respecto a las recomendaciones científicas relacionadas con la pandemia COVID-19 (Caponi, 2020).

El impacto sociológico de las fake news en los espacios públicos también está directamente relacionado con los algoritmos que utilizan las redes sociales, que filtran el contenido que se le expondrá a la persona, a partir de las visiones políticas y sociales que tiene el usuario, creando las llamadas "cámaras de eco ideológicas" (Rosenzweig, 2017; Sunstein, 2001). Considerando que cada integrante de la burbuja está expuesto selectivamente a las opiniones con las que está de acuerdo, se desarrolló un fenómeno social, denominado "efecto falso consenso", que se traduce en una tendencia a sobreestimar lo común que es la opinión en sí misma (McDougall et al., 2018). Estas comunidades "se vuelven cada vez más segregadas en cuanto a política, cultura, geografía y estilo de vida" (Kakutani, 2018, p. 105), contribuyendo a la constitución de una sociedad polarizada y fragmentada, con el deterioro del sistema democrático (Fisher \& Taub, 2018; Levitsky \& Ziblatt, 2018; Recuero \& Gruzd, 2019).

Sin embargo, además de las cuestiones teóricas, los acontecimientos recientes han demostrado los efectos prácticos deletéreos de la difusión de noticias falsas para el proceso democrático y el ejercicio de la ciudadanía.

\section{Materiales y métodos}

La mayoría de las incursiones científicas en las fake news se han centrado en cuestiones de producción, como la ubicación y las posibles motivaciones de varios proveedores de desinformación, el cambiante panora- 
ma geopolítico de la guerra de la información, los beneficios económicos para los medios. mecanismos de comunicación y búsqueda y la necesidad y conveniencia de implementar restricciones técnicas y/o financieras que minimicen la difusión de noticias falsas, entre otras. El enfoque en temas de producción es importante y todos estos son casos válidos cuya discusión es pertinente. Sin embargo, este artículo, aunque aborda algunos de los puntos anteriores, pretende abordar algunas dinámicas de recepción crítica que podrían estar subyacentes a la mayor presencia de noticias falsas en el entorno contemporáneo que en el pasado.

Por tanto, destaca como especialmente relevante un enfoque interseccional entre Sociología y Derecho, para entender no solo cómo abordar el problema de manera legislativa, sino también cómo interpretar su advenimiento desde los contextos históricos, sociológicos y culturales que le sirvieron de cuna, es decir, la posmodernidad y la posverdad, eligiendo esto como panorama teórico.

En este sentido, el trabajo realiza un breve análisis de las medidas que se han utilizado alrededor del mundo para enfrentar el problema, con una breve reflexión crítica sobre su efectividad relativa, a partir tanto de las estructuras teóricas previamente establecidas como de los datos empíricos que han sido planteados por las Ciencias Humanas y Sociales.

\section{Discusión y conclusiones}

\section{¿La regulación estatal es suficiente para el problema?}

Una exploración de las bases sociológicas e históricas del problema, a pesar de su comprensión esencial, es solo el primer paso para enfrentar el problema de las noticias falsas. Es imperativo proceder, en un segundo momento, a correlacionar estos aportes teóricos con los datos empíricos que rodean el tema, tanto en lo que respecta a su efectividad práctica, como en relación con las consecuencias de tales medidas para temas sensibles de derechos humanos, tales como libertad de expresión.

Las medidas para combatir la difusión de noticias falsas se pueden clasificar, en general, en tres tipos: leyes reguladoras de medios públicos; solicitud de regulación privada de plataformas privadas (por ejemplo, verificación de datos de Facebook); y educación mediática de la población, con miras a 
sensibilizar al individuo sobre la importancia de una postura crítica en relación con los contenidos difundidos en las redes digitales, como ejercicio de ciudadanía (Cardoso et al., 2018).

El uso de una legislación restrictiva es posiblemente la solución que se propone con mayor frecuencia en la materia, que suele hacerse con base en conceptos como "derecho a la comunicación" (Vannuchi, 2018) o consideraciones sobre la necesidad de poner límites al derecho a la libertad. expresión (Balem, 2017).

Esta fue la estrategia adoptada por Italia, a través de un proyecto de ley que penalizaba la publicación o divulgación de "noticias falsas, exageradas o tendenciosas", con una previsión de multa de hasta 5000 euros, con una combinación de prisión a más noticias falsas graves - como las que pueden incitar a la delincuencia o la violencia-e imposición en las redes sociales que monitorean sus plataformas en busca de dicho contenido (Tambini \& Goodman, 2017). Otros países, como Alemania y el Reino Unido, han adoptado políticas regulatorias similares (Cardoso et al., 2018).

Sin embargo, se ha observado que acciones en esta dirección tienden a generar fricciones con los derechos humanos y muchas veces degeneran en autoritarismo. Esta fue la conclusión de un informe titulado "Fake news: respuestas de política pública", en el que se evaluaron críticamente las políticas públicas adoptadas por China e Italia con miras a abordar las falsas noticias, así como sus respectivas consecuencias en el ámbito de los derechos humanos. El informe concluyó que China es una ilustración útil de los peligros presentes tanto en el establecimiento de estructuras regulatorias preventivas (antes de la publicación) como en la definición muy amplia de lo que constituye una noticia falsa o un rumor, un concepto que, para el gobierno chino, incluye "socavar la moral, el sistema socialista y la autenticidad de la información” (Tambini, 2017, p. 13). Así, China "es un ejemplo de un país que eligió como respuesta pública la práctica de limitar agresivamente la libertad de expresión" y terminó adoptando una "definición demasiado amplia de lo que constituyen noticias falsas o rumores/rumores" (Cardoso et al., 2018, p. 25).

El informe concluye que estas circunstancias explican por qué los defensores internacionales de la libertad de expresión, como el Relator Especial de la ONU para la Libertad de Expresión y el Representante de la OSCE para la Libertad de los Medios de Comunicación, han denunciado abiertamente los riesgos derivados de abordar las fake news a través de la regula- 
ción estatal (Tambini \& Goodman, 2017). Problemas similares se han observado en los sistemas privados de verificación de datos, siempre relacionados con la imposibilidad de garantizar la exención del agente responsable de evaluar la noticia.

Un hecho particularmente notable en este contexto de discusión es la (aquí llamada) Doctrina de la Equidad, que ejemplifica la relación entre el aspecto individual y la función democrática de la libertad de pensamiento y expresión, siendo - para Patricia Aufderheide (1990) - un lugar de gran controversia sobre el futuro de la regulación del interés público.

Jonathan Andrew Stewart Honig (2019) resume que la Doctrina de la Equidad fue la construcción fundamental de las regulaciones de televisión y una de las regulaciones de contenido más controvertidas que ha sido aplicada a las estaciones de televisión en los Estados Unidos por la Federal Communications Commission (FCC). En 1949, esta comisión gubernamental organizó un marco regulatorio para los medios del país, que se conoció como Fairness Doctrine, aquí traducida libremente como Doctrina de la Equidad.

En general, esta doctrina tuvo el objetivo de promover la discusión de temas controvertidos de vital interés para la comunidad y brindar espacio para diferentes puntos de vista sobre estos temas (Hazlett, 1989). Souza y Pinheiro (2016) comentan que esta doctrina se desarrolló a partir de la idea de que para que exista el derecho a la información no basta con que la libertad de prensa se garantice solo bajo el prisma de la abstención estatal, ya que esto podría implicar la exclusión de grupos desfavorecidos del discurso público y la manipulación de la libertad por parte de grupos hegemónicos o mayoritarios. Además de desarrollar un sistema federal de licencias para las emisoras, la FCC identificó ciertos tipos de discurso como esenciales para mantener el estándar de interés público, y esto en términos de prioridad (Hazlett \& Sosa, 1997).

La Doctrina de la Equidad, en términos objetivos, requería que las estaciones de radio y televisión que tenían licencias de transmisión emitidas por la Comisión Federal de Comunicaciones (FCC) (1) dedicaran parte de su programación a temas controvertidos de importancia pública y (2) para permitir la presentación de puntos de vista opuestos sobre estos temas. Esto significaba que los programas de políticas deberían incluir puntos de vista opuestos sobre el tema en discusión. Las emisoras tenían el deber activo de determinar el espectro de opiniones sobre un tema determinado e incluir a las personas más adecuadas para representarlas en su programación. 
Además, la regla requería que las emisoras alertaran a cualquier persona sujeta a un ataque personal a su programación y les dieran la oportunidad de responder, y exigía que todas las emisoras que respaldan a candidatos políticos inviten a otros candidatos a responder.

Esta política comenzó en la Ley de Radio de 1927, cuando el Congreso dictó que la FCC (y su predecesora, la Comisión Federal de Radio) solo debería emitir licencias de transmisión cuando fuera útil al interés público. En 1949, la FCC interpretó esto de manera más estricta en el sentido de que los licenciatarios debían incluir discusiones sobre asuntos de importancia pública en sus transmisiones y que debían hacerlo de manera justa. Posteriormente, la agencia publicó una norma en materia de editorialización por los licenciatarios de radiodifusión, que dio a conocer la llamada Doctrina de la equidad y comenzó a aplicarla.

Sin embargo, la Doctrina de la Equidad ha enfrentado varios desafíos a lo largo de los años. Al principio, la constitucionalidad de la doctrina fue probada y confirmada por la Corte Suprema de los Estados Unidos en un caso histórico de 1969, Red Lion Broadcasting Co., Inc. v. FCC (395 EE.UU. 367). Aunque el Tribunal luego falló en el sentido de que la doctrina no violaba los derechos de la Primera Enmienda de la emisora, el Tribunal advirtió que, si la doctrina comenzaba a restringir la expresión, entonces la constitucionalidad de la regla debería reconsiderarse. Apenas cinco años después, sin declarar inconstitucional la doctrina, la Corte concluyó en otro caso que la doctrina "debilita ineludiblemente el vigor y limita el alcance del debate público" (Miami Herald Pub. Co.v. Tornillo, 418 U.S. 241). En 1984, la Corte concluyó que la justificación de la escasez subyacente a la doctrina era defectuosa y que la doctrina estaba limitando la amplitud del debate público (FCC v. League of Women Voters, 468 U.S. 364). Esta decisión preparó el escenario para la acción de la FCC en 1987. Un intento del Congreso de restablecer la regla por estatuto fue vetado por el presidente Ronald Reagan en 1987, y los intentos posteriores ni siquiera fueron aprobados por el Congreso (Aufderheide, 1990).

En respuesta, la FCC comenzó a reconsiderar la regla a mediados de la década de 1980 y finalmente la derogó en 1987, luego de que el Congreso aprobara una resolución que ordenaba a la comisión que estudiara el asunto. A la decisión se le atribuyó la explosión de la radio conservadora a fines de la década de 1980 y principios de la de 1990. Aunque la FCC no ha hecho cumplir la regla en casi un cuarto de siglo, técnicamente permanece en los 
libros. Como parte de los esfuerzos más amplios de la administración Obama para revisar la regulación federal, la FCC finalmente está descartando la regla de una vez por todas.

Una vez comprendido el contenido histórico, parece que la Doctrina de la Equidad fracasó en su propósito al no hacer explícitos los criterios para la realización de su alcance. Sobre este punto, Thomas W. Hazlett comenta que:

El uso de cualquier estándar arbitrario para otorgar licencias a la prensa [...] seguramente causará un gran daño político, incluso si el estándar parece tan inocente como la "justicia”. Después de todo, la justicia está en el ojo del espectador y los funcionarios del gobierno son observadores muy interesados. [...]. Cuanto más subjetivo es el patrón, [...] más nervioso está el suplicante. La FCC nunca ha definido claramente el requisito de equidad para los licenciatarios, prefiriendo en cambio adherirse a un método fácil de usar. [...] la concesión de licencias de radio federal comenzó en la década de 1920 con el estándar de atribución más vago que los tribunales permitirían: los derechos deberían otorgarse a cualquiera que satisfaga "la conveniencia, el interés o la necesidad del público". En los primeros días de la radio, el secretario de Comercio, Herbert Hoover, consideró que las opiniones de las organizaciones laborales eran menos de interés público que las de los empresarios y distribuyó valiosos derechos de espectro en consecuencia. Franklin Roosevelt consideró eminentemente justo prohibir a todos los editores de periódicos ser propietarios de estaciones de radio... con el argumento de que, como clase, eran injustamente hostiles al New Deal. (Hazlett, 1989, pp. 104-105, traducción libre, énfasis agregado)

Si bien la libertad de expresión y de prensa tradicionalmente significa la ausencia de controles estatales, la base lógica para la regulación de la transmisión es que la libertad permite el prejuicio, como lo demuestra Hazlett (1989). Se considera necesaria una regulación con mentalidad pública para garantizar la igualdad de acceso a los medios de comunicación para todos los lados de las controversias y, en definitiva, para promover la igualdad de trato de los candidatos políticos, para mitigar la posible parcialidad de los editores. Por supuesto, hay noticias grotescamente injustas e incluso programas de entretenimiento irresponsables. Sin embargo, la pregunta relevante es si la regulación política tenderá a reducir la desigualdad o exacerbar los prejuicios y acabar con las fuentes de noticias importantes. La regulación traslada la decisión de programación de "justicia" de aquellos que compiten por audiencias a aque- 
llos que han asegurado el poder burocrático dentro de una agencia federal. Se necesita un gran acto de fe para creer que este reemplazo mejorará.

\section{La alfabetización digital como alternativa}

Los riesgos de la regulación de los medios estatales como herramienta para combatir las fake news han animado a investigadores y agentes públicos a buscar alternativas que no tengan el mismo potencial nocivo para la libertad de expresión, destacando, en este sentido, la noción de "alfabetización digital" (digital literacy), directamente vinculado al concepto de "ciudadanía digital". Si bien es un constructo sumamente amplio, para el que diferentes autores presentan definiciones considerablemente divergentes, se puede decir, en general, que la ciudadanía digital está relacionada con la capacidad de la persona para participar en el espacio en línea de la sociedad, incluida tanto la conectividad a la propia Internet como las habilidades necesarias para su uso (Mossberger et al., 2007). El Consejo de Europa lo define como "la capacidad de participar de manera positiva, crítica y competente en el entorno digital" (McDougall et al., 2018, p. 12).

La alfabetización digital, a su vez, trasciende la mera capacidad de obtener o utilizar información en línea de forma instrumental, englobando también, más específicamente, la capacidad de hacer preguntas sobre la fuente y el significado de la información, sobre los intereses involucrados en su transmisión, en definitiva, comprender cómo la información se relaciona con las fuerzas sociales, políticas y económicas (Buckingham, 2015, p. 15). Es, en esencia, un tipo de capacidad ética y social que complementa las habilidades técnicas y prácticas necesarias para el uso de tecnologías digitales (McDougall et al., 2018, p. 12).

Varias investigaciones han demostrado que la educación en alfabetización mediática puede tener resultados positivos en el conocimiento, las habilidades y las actitudes de los estudiantes para analizar críticamente y comprender los medios (Jeong et al., 2012; Vraga \& Tully, 2016; Webb \& Martin, 2012). Más que eso, los estudios han demostrado que este tipo de educación es especialmente eficaz cuando se trata de prevenir la creencia en noticias falsas, con investigaciones que muestran que el nivel de alfabetización mediática de un individuo es inversamente proporcional a su probabilidad de creer y compartir noticias falsas (Kahne \& Bowyer, 2017). 
La superioridad de este enfoque sobre la regulación estatal también está relacionada con los fenómenos cognitivos humanos llamados "sesgo de confirmación" y "sesgo de desconfirmación", que describen la tendencia a, ante la evidencia que desafía nuestras opiniones, y que, por lo tanto, debería motivarnos a reexaminar nuestros puntos de vista, reaccionar con un impulso psicológico para aferrarnos aún más firmemente a nuestras creencias erróneas, en ambas direcciones: buscar la confirmación de nuestras creencias anteriores, en lugar de información que pueda contradecirlas o complicarlas (sesgo) confirmación); e ignorar o rechazar información que desafíe las convicciones personales (sesgo de desconfirmación), con la propensión, en el caso de información del espacio mediático, a descalificar a los medios como deshonestos y tendenciosos (McDougall et al., 2018), o, en el caso de caso de regulación estatal, para calificar al Poder Público como autoritario y conspiracionista. Así, paradójicamente, la lucha legislativa contra la desinformación puede, en algunos puntos, intensificarla.

La educación en alfabetización mediática, a su vez, ha sido eficaz incluso para mitigar los efectos del sesgo de confirmación, con el potencial, por tanto, de tratar el fenómeno de las fake news en su raíz: la incapacidad de una buena parte de la población para aceptar información. que cumpla con sus convicciones personales (Miller, 2016). Por este motivo, la Comisión Europea ha destacado reiteradamente la importancia del desarrollo de la alfabetización mediática digital como instrumento para lograr la ciudadanía y prevenir las fake news, tanto porque es una medida que no viola las libertades individuales, como porque es uno de los pocos enfoques que tiene eficacia a largo plazo (Comisión Europea, 2018).

A pesar de que las cuestiones relacionadas con la metodología de dicha instrucción (grupo de edad a aplicar, responsable del ministerio, nivel escolar a insertar) son objeto de considerables altercados (Jeong et al., 2012; McDougall et al., 2018, p. 12), existe una consonancia sobre los beneficios positivos a largo plazo de la educación digital para combatir la desinformación y prevenir la difusión de noticias falsas.

Los beneficios de optar por la alfabetización digital, frente a la regulación estatal, son varios y están relacionados no solo con la efectividad en la prevención de la desinformación, sino también con el mantenimiento de la libertad de expresión y con la maduración de responsabilidades y capacidades relacionadas con la ciudadanía, con todos los efectos a largo plazo que resultan de una sociedad maduraron en ese momento (Cardoso et al., 2018). 
La inclusión de este tipo de enseñanza en los planes de estudio de las escuelas, tanto privadas como públicas, tiene el potencial de permitir que la propia población se enfrente al revuelo de la desinformación y, por lo tanto, se dé cuenta de su ciudadanía digital.

Finalmente, la educación digital es una vía preferible porque, como lo recuerda Bobbio (1990, p. 214), es mejor "una libertad siempre en peligro, pero expansiva, que una libertad protegida, pero incapaz de desarrollarse. Solo una libertad en peligro es capaz de renovarse. Una libertad incapaz de renovarse tarde o temprano se convierte en una nueva esclavitud".

\section{Consideraciones finales}

No hay fin a esta lista de venenos de acción instantánea, para los cuales el único antídoto sigue siendo la investigación minuciosa de la verdad de los hechos, ya que los "reyes" de hoy, individuales o colectivos, también están bajo dios. Pero cuesta mucho tiempo y mucho dinero, elementos que son cada vez más escasos en el mundo del periodismo profesional (Mesquita, 2018). De hecho, el fenómeno de la difusión de noticias falsas como estrategia política — como ocurrió en las últimas disputas presidenciales en Estados Unidos y Brasil - ha comprometido en gran medida la calidad del debate público y sesgado la comprensión de la realidad social en el ámbito político-partidista.

Como se explicó en la primera parte de este estudio, las fake news son la principal herramienta para la construcción metanarrativa de discursos que pretenden alterar, bajo la dirección de propósitos políticos, la comprensión pública de los hechos. En este sentido, las democracias liberales parecen acercarse a su ocaso, o al menos sufren una fuerte amenaza bajo el auspicio de la formación de verdaderas milicias digitales, como se ha visto en el ámbito reaccionario nacional.

Una solución continuamente ventilada es la regulación del Estado, con el propósito de limitar la difusión de noticias falsas o incluso criminalizar su práctica, como en el caso del Proyecto de Ley No. 2630, de 2020, conocido como Ley de Noticias Falsas. La cuestión es que la construcción de discursos alternativos o diferentes interpretaciones son típicas de la experiencia social. Como se muestra en la exposición Doctrina de la equidad, este intento no logró preservar el interés público al no establecer criterios objetivos 
para otorgar licencias a estaciones de radio y televisión. Sin embargo, dado que la expedición de las licencias estaba en manos de agentes del gobierno, su liberación implicó estar sujeta a intereses políticos, así como a legislación que pretende criminalizar la difusión de noticias falsas.

Al final, este estudio apostó por la alfabetización digital como herramienta adecuada no solo para mitigar los efectos de las fake news, sino también para la realización de la ciudadanía digital de los ciudadanos. Este enfoque tiene la ventaja de mantener sólida la libertad de expresión y de opiniones de las personas. no limitar la libertad de expresión. Además, sin embargo, también ha mostrado particular efectividad como solución a largo plazo del problema, ya que, en lugar de evitar que la desinformación llegue al individuo (objetivo cuya plena implementación es materialmente imposible), habilita y capacita al sujeto para evaluar críticamente el contenido recibido.

Para usar una analogía pertinente al momento global actual, la regulación estatal correspondería a la imposición de medidas de distancia social; sin duda son necesarios en este momento, pero no pueden, por sí mismos, eliminar la contaminación por el virus, sino mitigar su propagación. La educación en alfabetización digital a largo plazo, por otro lado, equivaldría al descubrimiento de una vacuna, una medida que tiene como objetivo no contener el elemento nocivo en sí, sino inmunizar a la población amenazada por él.

\section{Bibliografía}

Almeida, R. de (2019). Bolsonaro Presidente: Conservadorismo, evangelismo e a crise brasileira. Novos Estudos CEBRAP, 38(1), 185-213. https://bit. ly/3bTVz6A

Arendt, H. (2014). Entre o passado e o futuro. São Paulo, Perspectiva.

Aufderheide, P. (1990). After the Fairness Doctrine: Controversial Broadcast Programming and the Public Interest. The Journal of Communication, 40(3), 47-72. https://doi.org/10.1111/j.1460-2466.1990.tb02270.x

Balem, I.F. (2017). O impacto das fake news e o fomento dos discursos de ódio na sociedade em rede: a contribuição da liberdade de expressão na consolidação democrática. $4^{\circ}$ Congresso Internacional de Direito e Contemporaneidade. Santa Maria, UFSM.

Barragán, A. (2018). Cinco "fake news" que beneficiaram a candidatura de Bolsonaro. Jornal Brasil El País. https://bit.ly/35UE4PG 
Bobbio, N. (1990). A era dos direitos. Rio de Janeiro, Ed. Campus.

Borges Júnior, E. (2019). What is the post-truth? Elements for a critique of the concept. Brazilian Journalism Research, 15(3), 524-545. https://doi. org/10.25200/BJR.v15n3.2019.1189

Buckingham, D. (2015). Defining digital literacy. What do young people need to know about digital media? Nordic Journal of Digital Literacy, 10, 21-35. https://bit.ly/3isbQ3H

Caponi, S. (2020). Covid-19 no Brasil: entre o negacionismo e a razão neoliberal. Estudos Avançados, 34(99), 209-224. http://dx.doi.org/10.1590/s01034014.2020.3499.013.

Castells, M. (1999). A sociedade em rede. A era da informação: Economia, Sociedade e Cultura. v. 1, $6^{\text {a }}$ ed. São Paulo, Paz e Terra.

Castells, M. (2018). Ruptura: a crise da democracia liberal. Rio de Janeiro, Zahar.

El País (2016). Papa compara consumo de notícias falsas com comer fezes. https:// bit.ly/3itQXVL

Fisher, M., \& Taub, A. (2018). How everyday social media users become real-world extremists. The New York Times. https://www.nytimes.com/2018/04/25/ world/asia/facebook-extremism.html

Frias-Filho, O. (2018). O que é falso sobre fake news. Revista USP, 116, 39-44. https://doi.org/10.11606/issn.2316-9036.v0i116p39-44

Genesini, S. (2018). A pós-verdade é uma notícia falsa. Revista USP, 116, 45-58. https://doi.org/10.11606/issn.2316-9036.v0i116p45-58

Giacoia Júnior, O. (2017). E se o erro, a fabulação, o engano revelarem-se tão essenciais quanto a verdade? Folha de S. Paulo. https://www1 folha.uol. com.br/ilustrissima/2017/02/1859994-e-se-o-erro-a-fabulacao-o-engano-revelarem-se-tao-essenciais-quanto-a-verdade.shtml

Hazlett, T.W. (1989). The fairness doctrine and the First Amendment. The Public interest, 96, 103-116.

Hazlett, T.W., \& Sosa, D.W. (1997). Was the Fairness Doctrine a "Chilling Effect"? Evidence from the Postderegulation Radio Market. The Journal of Legal Studies, 26(1), 279-301. https://bit.ly/392W5NM

Hobbs, R. (2017). Teach the Conspiracies. Knowledge Quest, 46(1), 16-24. https:// bit.ly/3sTAPC7

Jeong, S.-H., Cho, H., \& Hwang, Y. (2012). Media Literacy Interventions: A Meta-Analytic Review. The Journal of Communication, 62(3), 454-472. https://doi.org/10.1111/j.1460-2466.2012.01643.x 
Kahne, J., \& Bowyer, B. (2017). Educating for Democracy in a Partisan Age: Confronting the Challenges of Motivated Reasoning and Misinformation. American Educational Research Journal, 54(1), 3-34. https://doi. org/10.3102/0002831216679817

Kakutani, M. (2018). The Death of Truth: Notes on Falsehood in the Age of Trump. Danvers, MA, Tim Duggan Books.

Levitsky, S., \& Ziblatt, D. (2018). How democracies die. Portland, Broadway Books.

McDougall, J., Zezulková, M., Van Driel, B., \& Sternadel, D. (2018). Teaching media literacy in Europe: evidence of effective school practices in primary and secondary education. NESET II Report. https://bit.ly/2XSaFRR.

McIntyre, L. (2018). Post-Truth. Cambridge, MA, MIT Press.

McIntyre, L. (2019). The Scientific Attitude: Defending Science from Denial, Fraud, and Pseudoscience. Cambridge, MA, MIT Press.

Mesquita, F.L. (2018). A pós-verdade levará à pós-democracia? Revista USP, (16), 31-38. https://doi.org/10.11606/issn.2316-9036.v0i116p31-38

Miller, A.C. (2016). Confronting Confirmation Bias: Giving Truth a Fighting Chance in the Information Age. Social Education, 80(5), 276-279. https://bit. ly/3is52TO

Mossberger, K., Tolbert, C.J., \& McNeal, R.S. (2007). Digital Citizenship: The Internet, Society, and Participation. Cambridge, MA, MIT Press.

Oxford.Oxford Word of the Year(2016). Oxford Languages.https://bit.ly/2M0GLIm Park, R.E. (1940). News as a Form of Knowledge: A Chapter in the Sociology of Knowledge. The American Journal of Sociology, 45(5), 669-686. https:// bit.ly/39LqlvI

Reale, G., \& Antiseri, D. (2014). Storia della filosofia. Dai presocratici ad Aristotele. vol. 1. Bompiani.

Recuero, R., \& Gruzd, A. (2019). Cascatas de Fake News Políticas: um estudo de caso no Twitter. Galáxia (São Paulo), 41, 31-47. http://dx.doi. org/10.1590/1982-25542019239035

Rosenzweig, A. (2017). Understanding and Undermining Fake News from the Classroom. Berkeley Review of Education, 7(1), 105-112. https://doi. org/10.5070/B87136743

Souza, E.B.; \& Pinheiro, V.S. (2016). Democracia e Liberdade de Expressão: O pluralismo julgado pelo Utilitarismo de Mill e pelo Liberalismo de Rawls. Revista Thesis Juris, 5(1), 119-144. https://doi.org/10.5585/rtj.v5i1.315 
Sunstein, C. R. (2001). Echo chambers: Bush v. Gore, impeachment, and beyond. Princeton, Princeton University Press

Tambini, D. (2017) Fake news: public policy responses. LSE Media Policy Project Series. Damian Tambini and Goodman, Emma (eds.), (Media Policy Brief 20). The London School of Economics and Political Science. https://bit.ly/2LM9Bwm

Vannuchi, C. (2018). O direito à comunicação e os desafios da regulação dos meios no Brasil. Galáxia (São Paulo), 38, 167-180. https://doi.org/10.1590/19822554232145

Vosoughi, S., Roy, D., \& Aral, S. (2018). The spread of true and false news online. Science, 359(6380), 1146-1151. http://dx.doi.org/10.1126/science. aap9559

Vraga, E.K., \& Tully, M. (2016). Effectiveness of a Non-Classroom News Media Literacy Intervention Among Different Undergraduate Populations. Journalism \& Mass Communication Educator, 71(4), 440-452. http:// dx.doi.org/10.1177/1077695815623399

Webb, T., \& Martin, K. (2012). Evaluation of a Us School-Based Media Literacy Violence Prevention Curriculum on Changes in Knowledge and Critical Thinking Among Adolescents. Journal of Children and Media, 6(4), 430-449. https://doi.org/10.1080/17482798.2012.724591

Fecha de envío: 2020/10/31; Fecha de aceptación: 2021/01/18;

Fecha de publicación: 2021/03/01 